\title{
Comentando comentários: questões de texto, género e corpus ${ }^{1}$
}

\author{
Matilde Gonçalves* \& João Carrilho** \\ *NOVA FCSH- CLUNL, **CLUNL
}

\begin{abstract}
:
Based on the process of constituting a corpus on the practices of commentary, the aim of this paper is to discuss and exemplify some aspects related to the collection and organization of that corpus. In this way, it will be evident that a linear methodology - definition of a corpus, research method, elaboration of the database, cataloguing of the material collected, creation of a search engine - necessary for the study of the comment is a complex task that motivates reflection both on the constitution of a corpus and on the characteristics of genre and text, supported by a heuristic and case-based reasoning methodology.
\end{abstract}

Keywords: text, genre, corpus, comment/commentary

Palavras-chave: texto, corpus, comentário

\section{Introdução}

Este artigo insere-se nas atividades do grupo de investigação Gramática \& Texto do Centro de Linguística da Universidade Nova de Lisboa, as quais visam, entre outras, descrever e compreender as práticas de linguagem relacionadas com o comentário.

A partir do processo de constituição de um corpus de comentários (G\&T.Comenta), pretende-se, no presente artigo, discutir e exemplificar alguns aspetos relativos à recolha e à organização desse corpus. Deste modo, evidenciar-se-á que uma metodologia linear - definição de um corpus, método de pesquisa, elaboração da base de dados, catalogação do material recolhido, criação de um motor de busca - necessária para o estudo do comentário - é uma tarefa complexa que motiva uma reflexão e uma problematização quer sobre a constituição de um corpus (Rastier, 2011), quer sobre as características textuais e genológicas (Adam, 1999; Bronckart, 1997; Gonçalves \& Jorge, 2019; Saussure, 2002). De facto, o processo de recolha evidenciou dois aspetos: 1) é necessário que se tenha uma ideia prévia relativa ao comentário para definir e constituir um corpus de comentários; 2) a catalogação dos comentários requer uma definição dos descritores, mas, por sua vez, esses descritores requerem um conhecimento preliminar do que é um comentário.

Assim, por forma a elucidar esse dilema, num primeiro momento, procurar-se-á traçar algumas características das práticas de comentários; num segundo momento, partir-se-á de exemplos concretos retirados do corpus para equacionar as inter-relações que se estabelecem entre contexto de produção/circulação dos comentários, géneros e textos; num terceiro e último momento, atentar-se-á na apresentação e discussão da catalogação e dos descritores. Estes três momentos são enquadrados pelo presente segmento introdutório e por um que visa fechar o presente artigo com algumas reflexões finais advindas do que se apresenta a seguir.

\footnotetext{
${ }^{1} \mathrm{O}$ presente trabalho é financiado por fundos nacionais portugueses, através da FCT - Fundação para a Ciência e Tecnologia, como parte do projeto do Centro de Linguística da Universidade NOVA de Lisboa - UID/LIN/03213/2020.
} 


\section{Comentário: género de texto?}

Considerada comum aos seres humanos, a atividade de comentar ou glosar, para além de possibilitar uma função de desambiguação e de elucidação de um enunciado (Blom, 2017), é constitutiva de toda a prática de linguagem. Em tempos remotos, o comentário pertencia a uma tradição ancorada, em particular, na literatura, na exegese dos textos bíblicos, na filosofia ou ainda na ciência (Boulègue, 2014; Goulet-Cazé (dir.), 2000); atualmente, com o advento do digital, apropriou-se das esferas de atividades vinculadas ao quotidiano, em particular, no que toca aos jornais e às redes sociais (Calabrese 2019; Teixeira, 2016), ultrapassando, portanto, as esferas de especialidade.

Outro aspeto a ter em conta na caracterização do comentário é a existência de uma grande diversidade, profusão e flutuação de noções e de etiquetas de associadas ao objeto em causa, que evidenciam características diversas agrupadas sob uma denominação comum: glosa, comentário, marginália ou escólios, no que toca a práticas mais antigas; opinião, comentário de leitor, comentário de especialista, entre outras, para as mais recentes. O exemplo que segue demonstra como a flutuação da denominação persiste até na apresentação do próprio texto:

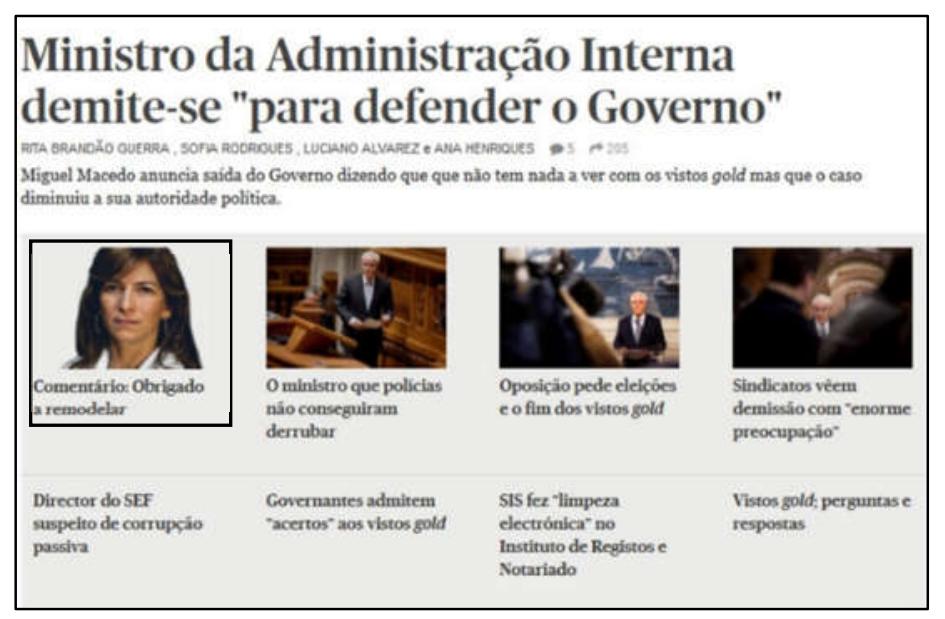

Texto 1. Primeira página do jornal Público de 16 de novembro de 2014

No texto 1, consta um texto intitulado "Obrigado a remodelar" categorizado como "comentário", mas, ao clicar no texto em questão (Texto 2), observa-se que o texto, assinado por Leonete Botelho, foi etiquetado, pela equipa editorial, como pertencendo ao género opinião, como se pode observar abaixo. 


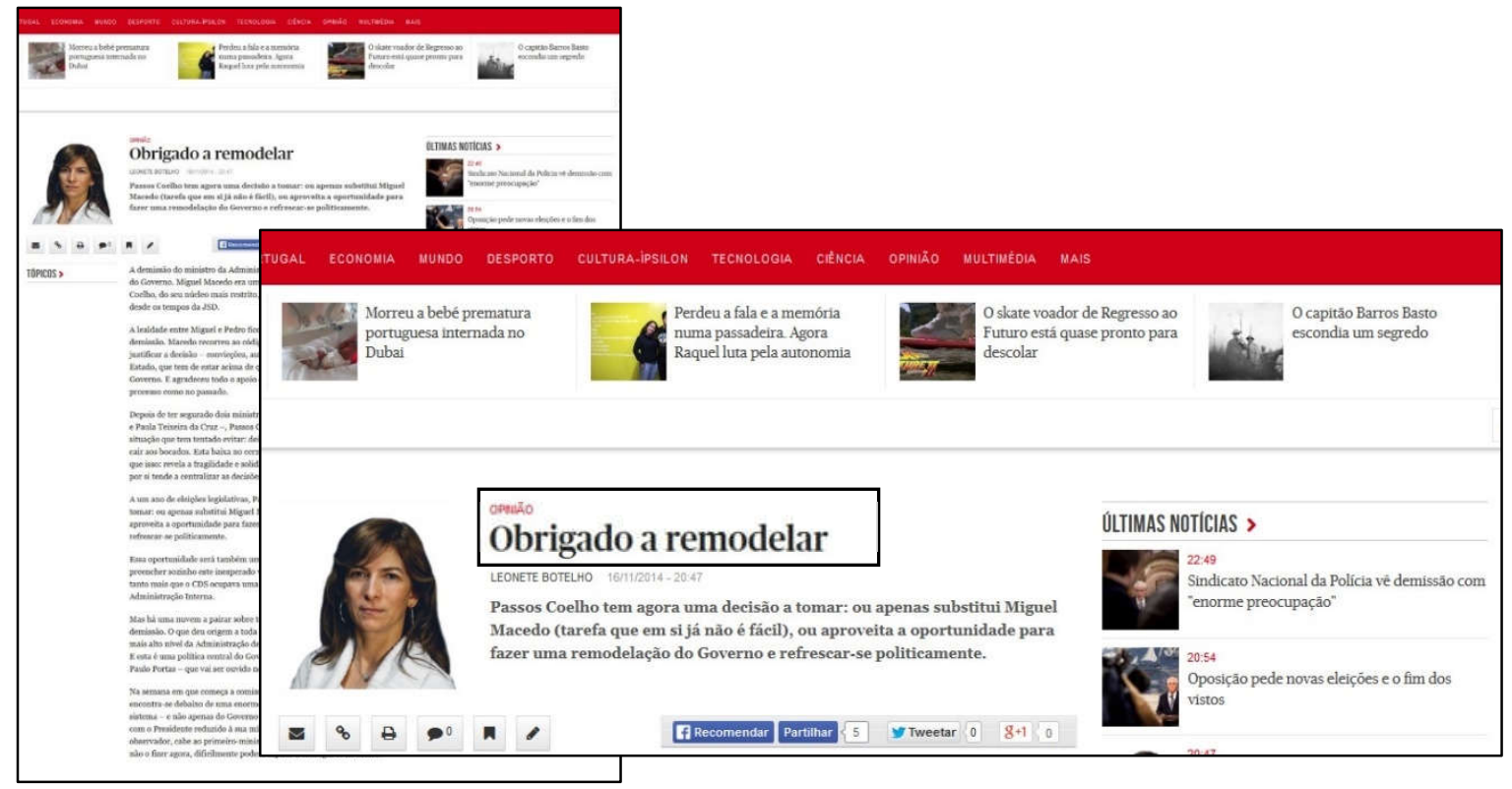

Texto 2: Texto intitulado "Obrigado a remodelar"

No tocante às funções, importa sublinhar que, embora no comentário de especialidade o propósito se concretize numa reflexividade sobre um determinado objeto textual e consequentemente reenvie a uma atividade do intelecto (Lévy, 2014), a questão da reflexividade tende a dissipar-se com o advento das redes sociais, nas quais se observa um amálgama entre comentário e diálogo (Calabrese, 2019). Neste caso, a troca e a rapidez das mensagens, assim como a presença de marcas enunciativas de pessoa tendem a deslocar o foco inicial de um texto sobre um outro texto para uma troca entre duas ou mais pessoas. Ainda nessa perspetiva, e como exemplo do que se avança, observa-se nos comentários das redes sociais um desvio da atenção do texto fonte para outros tópicos advindos da multiplicação em cascata da atividade comentadora (Paskin, 2010), promovida pelo quadro "conversacionalizante" (retomamos aqui a expressão de Paveau, 2017), oriundo da arquitetura dessas plataformas de comunicação digital.

Dentro da profusão e multiplicação das manifestações do comentário, quais serão os aspetos comuns? Pode-se certamente afirmar que todas têm em comum a existência de um segundo texto relativo a um primeiro texto ou tópico, que visa especificar ou diversificar o conteúdo do primeiro. Destarte o comentário é por essência intertextual. Outra questão a ter em conta relativamente aos aspetos comuns entre comentários prende-se com a capacidade de estes viabilizarem a regulação e a estruturação das atividades/ações humanas de ordem não verbal ou geral (Bronckart \& Bulea, 2006). Ainda nesta ótica, Calabrese (2019) sublinha que o comentário nas diversas disciplinas - filológica, filosófica, religiosa, ou histórica - possui um caráter normativo. De facto, a prática do comentário procura instaurar um modo de leitura canónica, com processos semelhantes às «procédures de contrôle et de délimitation du discours» (Foucault, 1971: 23).

De acordo com o exposto, fica claro que a noção de comentário evoluiu ao longo do tempo, quer pelo contexto de uso (inicialmente mais académico e atualmente mais quotidiano e digital), quer pelo foco (outrora sobretudo em textos e recentemente em objetos semióticos de ordem diversa como textos, vídeos, fotografias). 
Perante a profusão de noções e de etiquetas associadas ao comentário, manifesta-se a tendência de o classificar como um género de texto (ou de discurso), distinguindo ainda os géneros autoriais e os conversacionais:

Contrairement au commentaire ancien et médiéval (littéraire, philosophique ou religieux), que l'on peut considérer comme un genre auctorial, le commentaire sur le Web relève plutôt des genres conversationnels. Ces derniers ne sont pas « des genres étroitement liés à des lieux institutionnels, à des rôles, à des scripts relativement stables. (Maingueneau 2007 : en ligne) (Calabrese, 2019 : 18)

Ou ainda como hipergénero:

$\mathrm{Vu}$ les transformations du genre [commentaire] au fil du temps, on peut le considérer comme un hypergenre à la suite de Maingueneau, car « si l'on accepte l'idée que le genre de discours est un dispositif de communication sociohistoriquement défini », les grandes catégories génériques « posent problème, car elles semblent indépendantes d'une époque ou d'un lieu précis » (Maingueneau 2017 : 84). C'est d'ailleurs ce que propose Philippe Jousset dans son article, où il considère le commentaire « comme un hypergenre, autant dire un régime énonciatif aux contours relativement indéfinis (Calabrese, $2019: 24)$.

As diversas classificações do comentário apresentadas por Calabrese, a partir dos trabalhos de Maingueneau, levantam várias questões. A primeira incide na distinção entre género autorial $v s$ género dialogal, de acordo com o princípio definido por Maingueneau, segundo o qual os géneros autoriais são impostos ao destinatário pelo autor e/ou editor sem que haja negociação do quadro comunicacional e estão presentes em diversas esferas, tal como a literária, filosófica, política, jornalística, com etiquetas paratextuais genéricas "ensaio", "meditação", "aforismo" (Maingueneau, 2017). Partindo do princípio de que o género é uma configuração que regula quer a produção, quer a interpretação de um texto (Bronckart, 1997; Rastier, 2011), é constituído, no processo de receção e interpretação, um pacto de leitura, no qual o leitor aceita (ou não) um determinado número de convenções e constrangimentos estabelecidos no texto pelo género. Ou seja, a imposição ou a ausência de negociação é intrínseca à natureza do género. Assim, a distinção entre género autorial ou dialogal é redundante e pouco pertinente no que toca às questões genológicas.

Para discutir a questão da necessidade (ou não) de criar a categoria de hipergénero e de a aplicar ao comentário, retomemos a citação de Maingueneau na sua totalidade:

"Si l'on accepte que le genre de discours est un dispositif de communication sociohistoriquement défini, on peut noter que des catégories comme «dialogue», « lettre », « journal »... posent problème, car elles semblent indépendantes d'une époque ou d'un lieu précis. À mon sens, il est préférable de les catégoriser comme des hypergenres (Maingueneau 1998b). Ces derniers imposent des contraintes très pauvres, un simple formatage. (Maingueneau, $2017: 84$ )

Pela citação, são observáveis uma ambivalência e uma incongruência: a primeira diz respeito à definição do género como dispositivo definido e estabilizado socio-historicamente e à caracterização de determinados objetos, tais como o diálogo, a carta, o jornal, como sendo independentes de um tempo e lugar específicos. Partindo da premissa de Maingueneau, depreende-se que esses objetos não pertencem à categoria género, tendo 
em conta a sua independência socio-espaço-temporal. De facto, a própria natureza e a existência de um género instituem traços definidos que permitem identificá-lo. Perante a ausência desses traços, a sua identidade deixa de existir. A segunda revela-se na comparação e no agrupamento de objetos de natureza distinta. Com efeito, se o diálogo e a carta são consensualmente considerados géneros, o jornal convoca uma outra questão não contemplada no raciocínio do autor, a saber o jornal como meio de circulação e/ou suporte, e não como género. Finalmente na argumentação de Calabrese não fica clara a natureza do comentário visto este ser definido como pertencendo simultaneamente a um género autorial e a um hipergénero.

Todavia, a linguista, no seu artigo, avança uma pista pertinente relativamente ao pensamento dos antigos sobre o comentário, pois estes consideravam-no como uma atividade: "Il faut aussi noter que pour les anciens, le commentaire relève d'une activité plus que d'un genre" (2019: 9). Assim, perante a diversidade, a profusão e a flutuação de noções e de características associadas ao género parece-nos mais judicioso equacionar o comentário como uma atividade global de linguagem, tal como definida por Bronckart e Stroumza (2002). Os textos, integrados numa atividade de linguagem, materializam a ação de linguagem, enquanto unidade psicológica e abstrata correspondendo às representações que o agente tem em relação aos contextos de ação. Deste modo, o produto resultante dessa atividade de linguagem consubstancia-se nas unidades linguísticas escolhidas para o efeito:

On peut d'abord définir l'activité langagière comme le phénomène collectif d'élaboration et de mise en circulation de textes dont la visée ultime est d'établir une entente sur ce que sont les contextes et les propriétés des activités en général; il s'agit d'une méta-activité, que (re-)sémiotise les représentations humaines dans le cadre des possibilités offertes par une langue naturelle. On peut, ensuite définir l'action langagière comme une partie de cette activité, dont la responsabilité est imputée à un agent singulier. Comme toute action, l'action langagière présente à la fois une dimension comportementale ou physique (...) et une dimension sociale (...). (Bronckart \& Stroumza, 2002: 223)

\section{Comentário como atividade e ação de linguagem}

Para evidenciar o comentário como pertencendo a uma atividade e concomitantemente como ação de linguagem, atentemos aos seguintes exemplos retirados do corpus do grupo de investigação Gramática e Texto: 


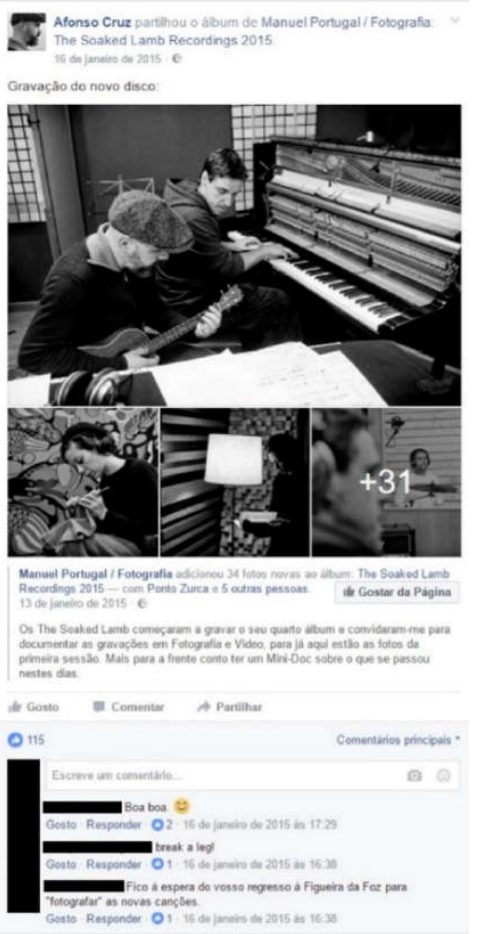

Texto 3. Comentário retirado do Facebook ${ }^{2}$

Este exemplo, retirado da página de Facebook de Afonso Cruz, escritor, ilustrador e músico português, patenteia a circulação e presença numa rede social: para além do nome da rede social, a organização global do texto, com uma publicação (post) na parte superior da página e os comentários dos leitores na parte inferior da página, observa-se a presença de unidades sémio-linguísticas, tais como "gosto", considerada como o "grau zero" do comentário (Deseilligny, 2019), “comentar" e "partilhar", unidades que incitam a uma ação específica do leitor e que podem ser consideradas como instrucionais.

Atente-se no comentário seguinte:

2 Para uma melhor legibilidade dos textos, ver anexos. 


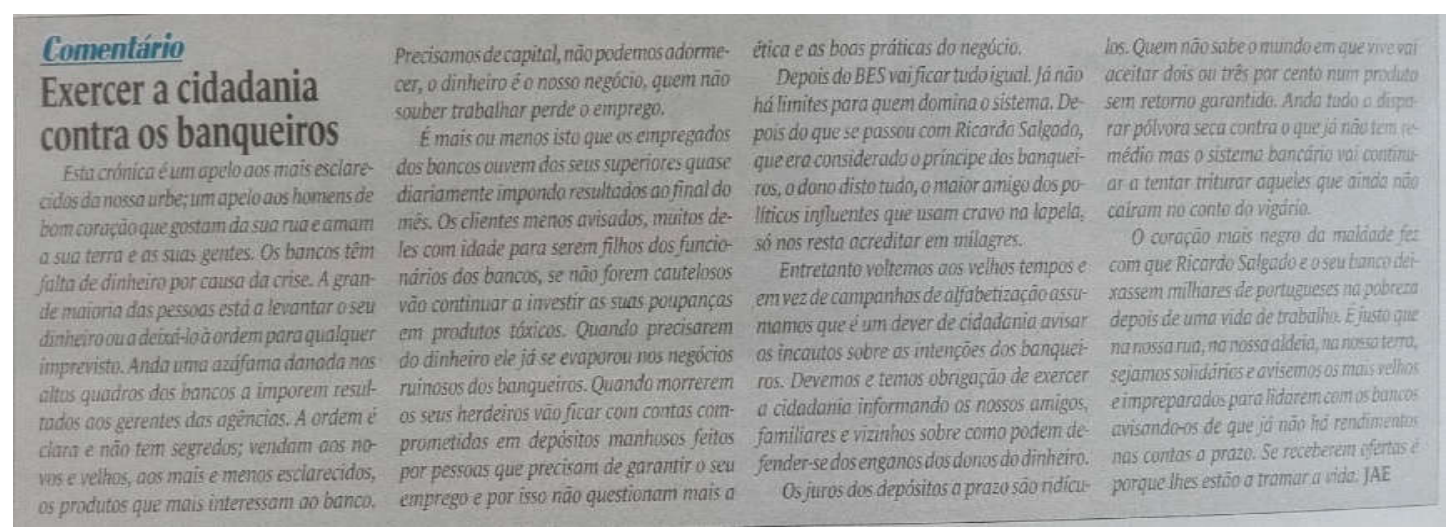

Texto 4. Comentário retirado do Jornal de Leiria

Este texto retirado do Jornal de Leiria, cujo autor é JAE (sigla utilizada pelo jornal), foi publicado a 2 de abril de 2015. Nas práticas de escrita jornalística encontram-se três níveis da construção dos textos (Maltais (dir.), 2010): um primeiro, relativo à transmissão da informação através da apresentação de factos; um segundo, atinente à interpretação dos factos pelo jornalista e, finalmente, o terceiro, construído pela opinião ou comentário da pessoa que produz o texto, através de juízos de valor sobre os factos. No exemplo em apreço, depreende-se que este pertence ao terceiro nível no qual é possível observar o ponto de vista de JAE relativamente aos bancos e à crise, com uma alternância entre a $3^{\mathrm{a}}$ pessoa do singular e a $1^{\mathrm{a}}$ pessoa do plural, com valor inclusivo (produtor + leitor). Para além disso, um outro aspeto chama a atenção: embora o texto esteja etiquetado como sendo um comentário, na primeira linha pode-se ler "esta crónica é um apelo", havendo, deste modo, duas formas diferentes de categorizar o texto. Este aspeto vem ao encontro da discussão apresentada anteriormente, referente à flutuação da denominação das diversas práticas do comentário.

Atente-se no comentário seguinte:
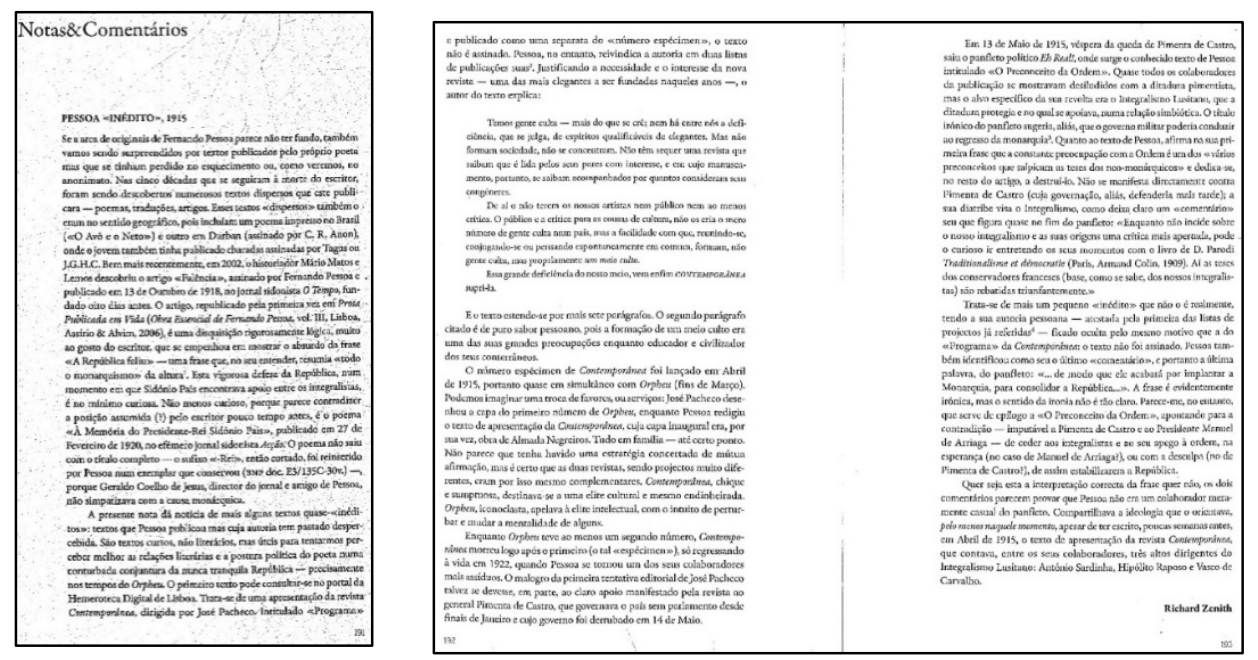

Texto 5. Comentário retirado da revista Colóquio e Letras 
O texto 5 tem como produtor Richard Zenith, investigador, crítico e escritor. Pelo papel social do produtor depreende-se que este comentário pertence à esfera académica e visa essencialmente apresentar textos desconhecidos de F. Pessoa, tal como se pode ler no próprio texto, "A presente nota dá notícia de mais alguns textos quase "inéditos": textos que Pessoa publicou mas cuja autoria tem passado despercebida". No texto, observa-se a presença de uma etiqueta genológica autorrefencial "nota", que explicita o género e que vem ao encontro das normas da revista Colóquio e Letras, como se pode ler no título da secção: "Notas e comentários".

Para além da apresentação dos textos de Pessoa, esta "nota" é igualmente constituída por uma vertente mais apreciativa com um posicionamento crítico do produtor patente pela presença da $1^{\mathrm{a}}$ pessoa do singular e do plural em "parece-me", "podemos imaginar", e com o recurso a expressões valorativas, como "puro sabor pessoano". Assim, este objeto textual coincide com a definição de comentário dada pelo $T L F i^{3}$ : "examen critique du contenu et de la forme d'un texte documentaire ou littéraire, en vue d'une lecture plus pénétrante de ce texte".

Nos exemplos apresentados, é de salientar a transformação e oscilação da noção de comentário em função das práticas e atividades quotidianas, jornalísticas, editoriais e académicas, ou ainda da evolução técnica e digital.

Pelo exposto, o caráter mutável e flutuante das práticas do comentário é incontestável, o que consequentemente influi na criação e organização do corpus de textos contendo a etiqueta "comentário", como a seguir apresentamos.

\section{Constituição do corpus: catalogação e descritores}

Tal como foi referido anteriormente, o projeto G\&T.Comenta tem como objetivo o estudo do comentário e a sua categorização enquanto atividade de linguagem e prática textual, mediante a análise de um corpus criada para o efeito. De forma a concretizar o projeto foram, inicialmente, delineadas as seguintes etapas: definição de um corpus e do método de pesquisa, elaboração da base de dados, catalogação do material recolhido, criação de motor de busca que possibilitasse aos utilizadores, de forma prática, as pesquisas necessárias aos seus estudos.

No entanto, pelo caráter pioneiro do projeto e pela natureza do comentário, tornou-se difícil seguir a metodologia linear primeiramente definida e fomos confrontados com um dilema de causalidade, apresentados sumariamente na introdução do presente trabalho:

1- A definição de um corpus de comentários requer que se tenha, à partida, um conhecimento que só o resultado do estudo pode trazer. Ou seja, se pretendemos com este estudo saber o que é um comentário e o que devemos considerar comentário, como podemos definir um corpus para o efeito?

2- A catalogação dos comentários requer uma definição dos descritores, mas, por sua vez, esses descritores carecem de um conhecimento prévio do material a catalogar, algo que se pretende alcançar com a base de dados.

Relativamente ao primeiro ponto, optámos por fixar um parâmetro que nos permitisse a recolha dos textos que viriam a constituir o nosso corpus. Decidimos, então, que as 'etiquetas', que surgem a catalogar os textos recolhidos, seriam o nosso ponto de referência. Ou seja, embora a definição 'comentário', que surge frequentemente a acompanhar os mais diversos textos nas mais diversas fontes, não signifique necessariamente que estamos perante um comentário (e possam existir textos que, não estando assinalados como comentário, de facto, o sejam), pensou-se que seria uma boa forma de definir um corpus inicial ao qual pudéssemos,

${ }^{3}$ TLFi : Trésor de la langue Française informatisé, ATILF - CNRS \& Université de Lorraine. Disponível em http://www.atilf.fr/tlfi 
posteriormente, acrescentar novos textos contendo comentários. Isto porque nos permitiria estabelecer um método de pesquisa (sabemos de forma prática o que procurar, temos um horizonte definido) e fixar um conjunto de características comuns a estes textos que nos permitissem perceber se as etiquetas correspondem de facto a um comentário. No gráfico 1, podemos ver a distribuição do nosso corpus pelas etiquetas:

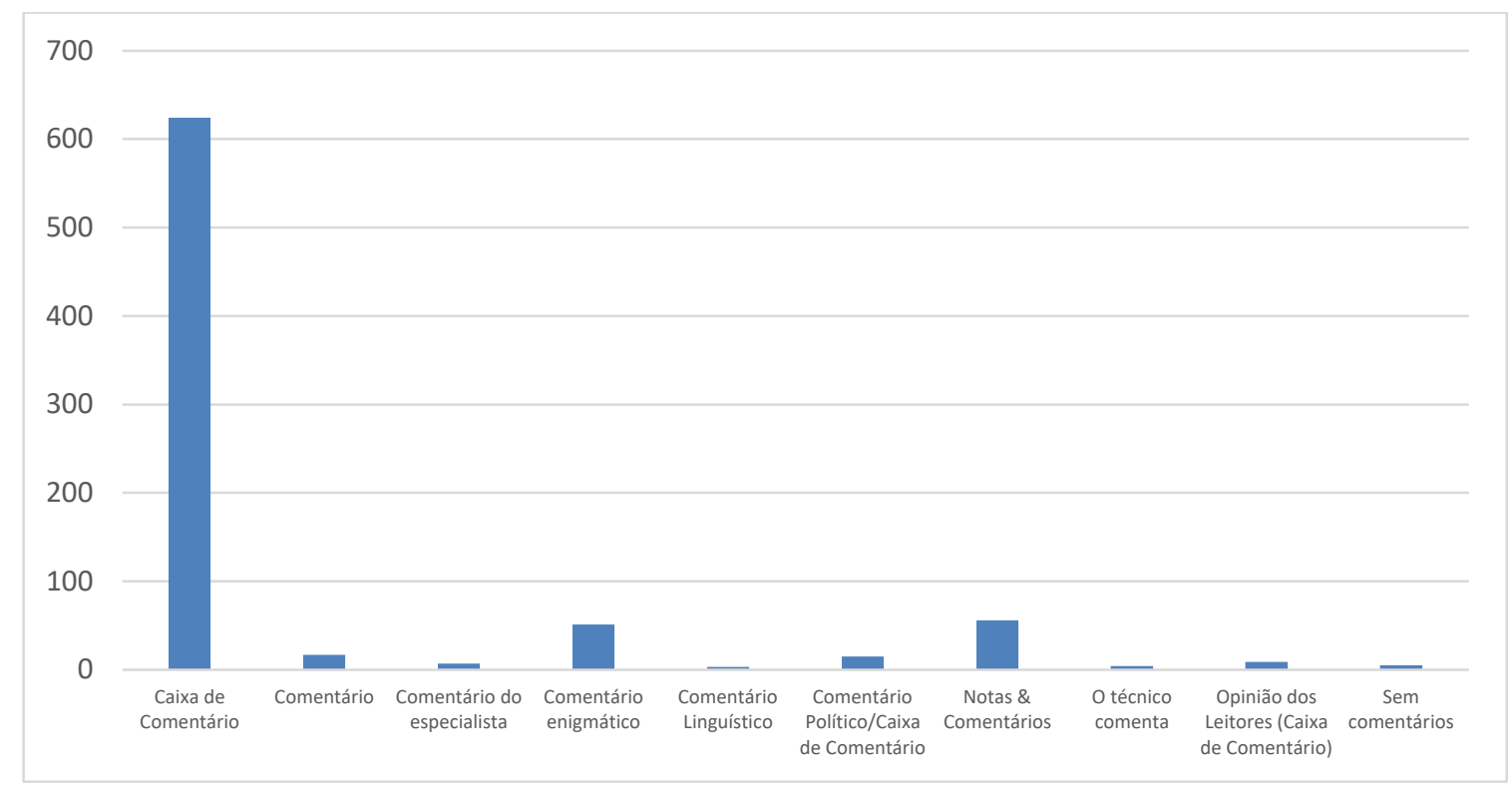

Gráfico 1: Distribuição do Corpus por Etiquetas

Do corpus constam 791 textos guardados em formato PDF e numerados de forma a que seja possível aceder-lhes pelo número que também constará da base de dados. Os comentários realizados em caixas de diálogo foram anonimizados e os ficheiros foram selados. Findo este processo, passou-se ao segundo ponto: o estudo do corpus com o objetivo de perceber que descritores devem constar da base de dados, permitindo as pesquisas necessárias e a realização de um motor de busca. Surgem então dois tipos de descritores:

1- Descritores essenciais à catalogação dos textos, isto é, que nos permitam apresentar cada elemento do corpus como peça única e bem definida consoante as suas características. É este o caso de Suporte, Meio de Circulação, Data, Autor, Título, Tipo de Comentário. Embora não tenhamos sempre toda a informação, é a associação dos vários descritores, que nos permite compreender de que texto se trata.

2- Descritores que, embora não sejam essenciais à identificação dos textos, são de extrema utilidade no que diz respeito aos estudos a realizar. É o caso de Etiqueta, Tema e Atividade.

Ainda que o título dos descritores seja bastante intuitivo relativamente ao seu conteúdo, torna-se essencial explicar a que nos referimos com Tipo de Comentário. Repare-se que não estamos a catalogar comentários, mas textos que contêm comentários, pois um textos pode conter diversos comentários e um comentário pode surgir em mais do que um texto. Uma Caixa de Comentários pode conter centenas de comentários, o que torna impraticável a catalogação de cada um. Nestes casos, a Data, Título e Autor referem-se ao texto comentado e 
não ao comentário. Por esta razão, da base de dados constam duas Datas (Comentário/Texto Comentado), dois Autores (Comentário/Texto Comentado) e dois Títulos (Comentário/Texto Comentado). É precisamente o descritor Tipo de Comentário que nos permite distinguir se estamos perante um texto catalogado por Comentário ou Texto Comentado.

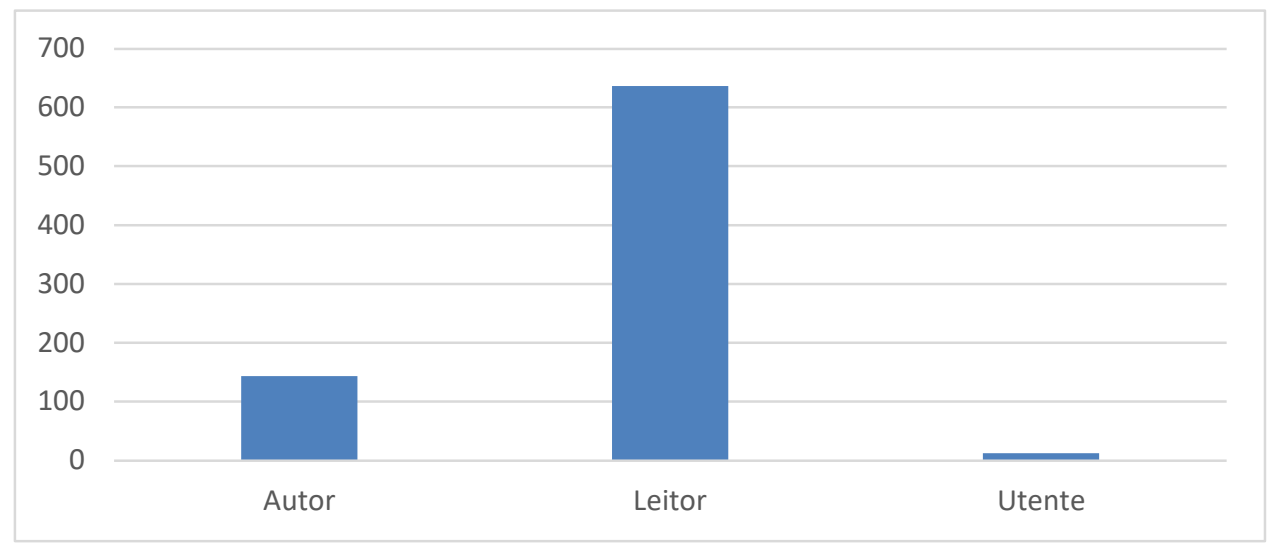

Gráfico 2: Distribuição do Corpus por Tipo de Comentário

Como podemos ver no Gráfico 2, temos três tipos de comentário. Os comentários de Leitor são os comentários efetuados em caixas de diálogo e, portanto, são catalogados por Data, Autor e Título do Texto Comentado. Os comentários de Utente são semelhantes aos comentários de Leitor, mas referem-se a sítios que apresentam um determinado produto (por exemplo site de alojamento ou vendas), referindo-se os comentários a um produto e não necessariamente a um texto presente no site. Os comentários de Autor são realizados por uma determinada personalidade (por exemplo um artigo num jornal ou numa revista) e, por isso, são catalogados por Data, Autor e Título do Comentário.

A base de dados está construída de forma a permitir análises numéricas e gráficas, que nos remetem de imediato para duas formas de expansão: Equalização e Amplificação.

-Equalização - existe um desnível enorme em alguns descritores. Por exemplo: o número de entradas em Suporte digital é superior ao físico; a Atividade jornalística é muito superior a todas as outras. Assim, justificar-se-ia o alargamento do corpus, para conseguir uma análise comparada mais viável.

Atente-se no seguinte gráfico: 


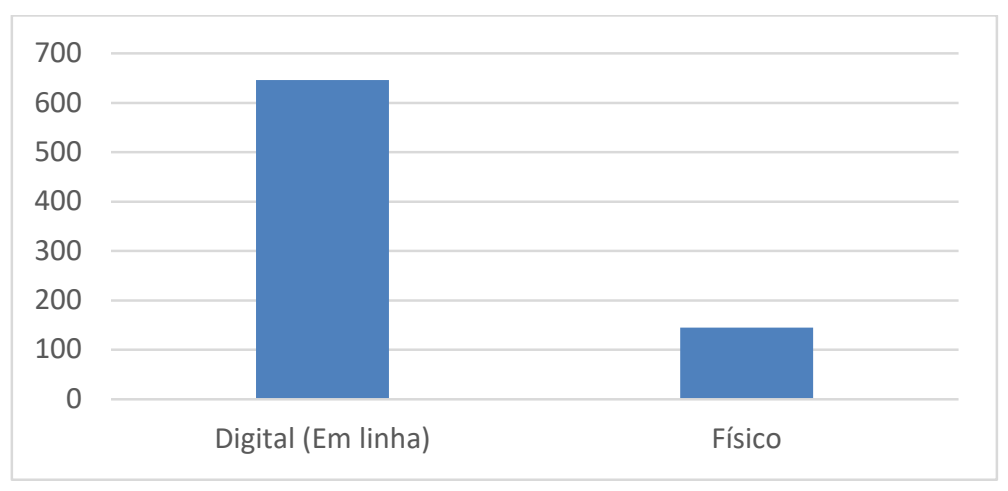

Gráfico 3: Distribuição do Corpus por Suporte

Atente-se no seguinte gráfico:

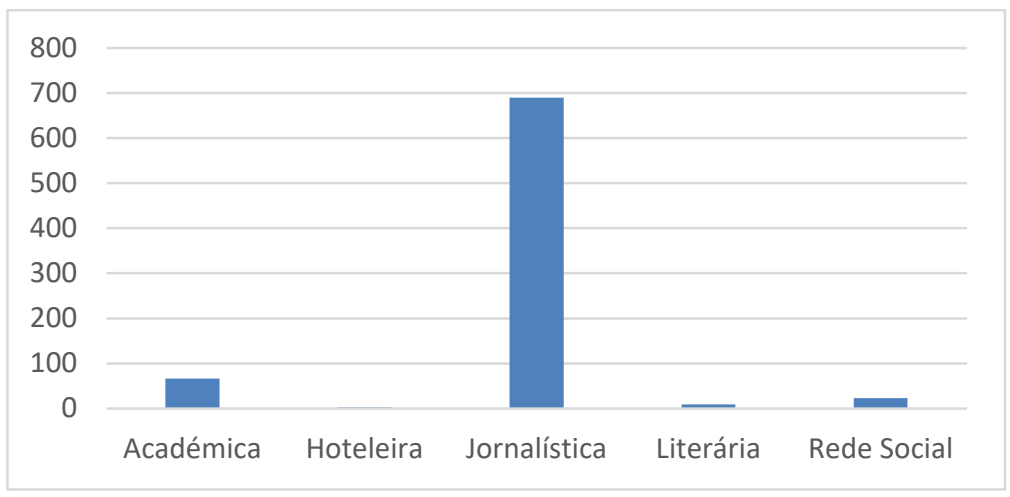

Gráfico 4: Distribuição do Corpus por Atividade

-Amplificação - Por exemplo: a análise da divulgação feita por particulares em rede social, ainda que esteja em reduzido número na base de dados, deixa antever uma complexidade enorme no que diz respeito à catalogação. Portanto, justifica-se focar este subgrupo do corpus e alargar o número de descritores, o que nos permitirá um grau de especificidade muito maior.

Está a ser construída a plataforma que nos permitirá disponibilizar, em linha, o corpus. Para além dos ficheiros PDF, os utilizadores terão também acesso a toda a informação inserida durante o processo de catalogação. A recolha dos textos em PDF deve-se à necessidade de manter a configuração original do texto, de forma a preservar a sua natureza empírica e complexa (Coutinho, 2017). Assim ao analisar o texto são tidos em conta, para além das unidades linguísticas, a presença de unidades não verbais, os fatores estruturais (plano de texto) e os fatores contextuais. Está, igualmente, em processo a conversão do formato PDF para TXT para pesquisas mais específicas, bem como a anexação destes ficheiros na plataforma digital. 


\section{Reflexões finais}

Mais do que apresentar um produto acabado, constituiu objetivo do presente artigo evidenciar o percurso seguido na constituição do corpus e da base de dados do comentário, convocando a diversidade, a flutuação e a indeterminação em torno das diversas práticas do comentário, bem como as decisões tomadas relativamente à catalogação e aos descritores e à sua organização.

De acordo com as propriedades textuais, contextuais e genológicas do objeto de estudo, da ordem da indicação e da sugestão e não necessariamente formais e sistemáticas, esse percurso assumiu contornos metodológicos heurísticos e não lineares (Marcushi, 2004/2009; Coutinho, 2017), semelhantes ao pensamento por caso (Case-based reasoning ou pensée par cas). De facto, a complexidade intrínseca do(s) texto(s) enquanto objetos de comunicação, e não redutíveis à vertente linguística que os compõe (Coutinho, 2017), apela à adoção de uma metodologia que possibilite descrever e compreender o(s) comentário(s). Durante o processo de constituição do corpus fomos confrontados com casos textuais que desafiavam a tomada de decisão relativamente aos descritores a adotar e à catalogação dos textos. Assim, o nosso trabalho pautou-se pelo método do pensamento por caso, referido anteriormente, que pode sumariamente ser definido como segue:

Description de cas (...) En ce sens, un cas n'est pas seulement un fait exceptionnel et dont on se contenterait qu'il le reste: il fait problème; il appelle une solution, c'est-à-dire l'instauration d'un cadre nouveau du raisonnement (...) redéfinir avec lui une autre formulation de la normalité et de ses exceptions. (Passeron \& Revel, 2005:11)

Em suma, o nosso trabalho consistiu em desvendar (algumas das) recorrências na imprevisibilidade (do sistema aberto) das práticas do comentário, com vista a conhecer e compreender as singularidades deste objeto. $\mathrm{O}$ percurso de descoberta e conhecimento ainda não se esgotou, precisamos de continuar a comentar os comentários.

\section{Referências:}

Adam, Jean-Michel (1999) Linguistique textuelle. Des genres de discours aux textes. Paris: Nathan.

Blom, Alderik (2017) Glossing the psalms. The emergence of the written vernaculars in western Europe from the seventh to the twelfth Centuries. Berlin/Boston: De Gruyter.

Bronckart, Jean-Paul (1997) Activité langagière, textes et discours. Pour un interactionnisme discursif. Lausanne: Delachaux et Niestlé.

Bronckart, Jean-Paul \& Stroumza, Kim (2002) Les types de discours comme traces cristallisées de l'action du langage. In Roulet, E. \& Burger, M. Les modèles du discours au défi d'un "dialogue romanesque": l'incipit de roman de R. Pinguet Le Libera. Nancy: Presses Universitaires de Nancy, pp. 213-263.

Bronckart, Jean-Paul \& Bulea, Ecaterina (2006) La dynamique de l'agir dans la dynamique langagière. In J.M. Barbier \& M. Durand (éds.) Sujet, activité, environnement : approches transverses. Paris: PUF, pp. 105134.

Boulègue, Laurence (ed.) (2014) Commenter et philosopher à la Renaissance: Tradition universitaire, tradition humaniste. Villeneuve d'Ascq: Presses universitaires du Septentrion. doi :10.4000/books.septentrion.5934

Calabrese, Laura (2019) Le commentaire : continuités et mutations d'un outil au service de la lecture et de l'écriture. In Calabrese, L. (coord.) Le commentaire du manuscrit à la toile. Revue de linguistique française et d'analyse du discours. Paris : Editions L'Harmattan. ISBN : 978-2-8066-3700-0, pp. 7-28. 
Coutinho, Maria Antónia (2017) Da natureza heurística da Teoria do Texto. Investigações 30, 2. pp. 153-172.

Deseilligny, Oriane (2019) La pratique du commentaire : un geste appareillé. In Calabrese, L. (coord.) Le commentaire du manuscrit à la toile. Revue de linguistique française et d'analyse du discours. Paris : Editions L'Harmattan, 11 (2), pp. 101-116.

Foucault, Michel (1971) L'ordre du discours. Leçon prononcée au Collège de France le 2 décembre 1970. Paris: Éditions Gallimard.

Goulet-Cazé, Marie Odile (dir.) (2000) Le commentaire, entre tradition et innovation. Paris : Vrin.

Gonçalves, Matilde \& Jorge, Noémia (2019) Promoção da literacia científica: balanço e perspetivas. In Caels, F., Barbeiro, L., Santos, J.V. (eds) Discurso académico: uma área disciplinar em construção. Coimbra/Leiria: CELGA-ILTEC, pp. 134-151.

Lévy, Carlos (2014) Quelques remarques introductives sur la genèse du commentaire philosophique. In Boulègue, L. (ed.) Commenter et philosopher à la Renaissance. Paris: Presses Universitaires du Septentrion, pp. 19-27. Disponível em : https://books.openedition.org/septentrion/5937.

Maingueneau, Dominique (2017) Genres de discours et web : existe-t-il des genres web ? In Barats, C. (ed.) Manuel d'analyse du web. Paris : Armand Colin, pp. 81-100.

Maltais, Robert (dir.) (2010) L'écriture journalistique sous toutes ses formes. Montréal: Presses de l'Université de Montréal.

Marcuschi, Luiz Antônio (2004/2009) Linguística do texto: o que é e como se faz? Recife: Editora Universitária da UFPE.

Paskin, Danny (2010) Say what?. Journal of International Communication, 16:2, pp. 67-83.

Passeron, Jean Claude \& Revel, Jacques (2005) Penser par cas. Paris : Éditions de l'EHESS.

Paveau, Marie Anne (2017) L'analyse du discours numérique. Dictionnaire des formes et des pratiques. Paris: Herman.

Teixeira, Carla (2016) Questões de semiótica e de gramática em comentários jornalísticos. Cadernos de linguagem e sociedade, 17(1), pp. 140-161. https://doi.org/10.26512/les.v17i1.4432.

Rastier, François (2011) La Mesure et le Grain: Sémantique de corpus. Paris: Honoré Champion.

Saussure, Ferdinand (2002) Écrits de linguistique générale. Paris: Gallimard.

\section{Outras referências}

Botelho, Leonor (2014) Obrigado a remodelar. In Público. 16 de novembro de 2014. https://www.publico.pt/ Consultado a 16 de novembro de 2014.

Cruz, Afonso (16 de janeiro de 2015). Gravação do novo disco. Facebook. https://www.facebook.com/permalink.php?story fbid=1617874095109457\&amp;id=157 (consultado a 29 de janeiro de 2015)

JAE (2015) Exercer a cidadania contra terceiros. In O Mirante (Vale do Tejo). Publicado a 2 de abril de 2015. Zenith, R. (2011) Pessoa «Inédito», 1915. In Revista Colóquio/Letras, Notas e Comentários, n. ${ }^{\circ}$ 176, pp. 191193. 


\section{Anexos:}

Afonso Cruz partilhou o álbum de Manuel Portugal / Fotografia The Soaked Lamb Recordings 2015

25 da laneirs de 2015 . 6

Gravação do novo disco

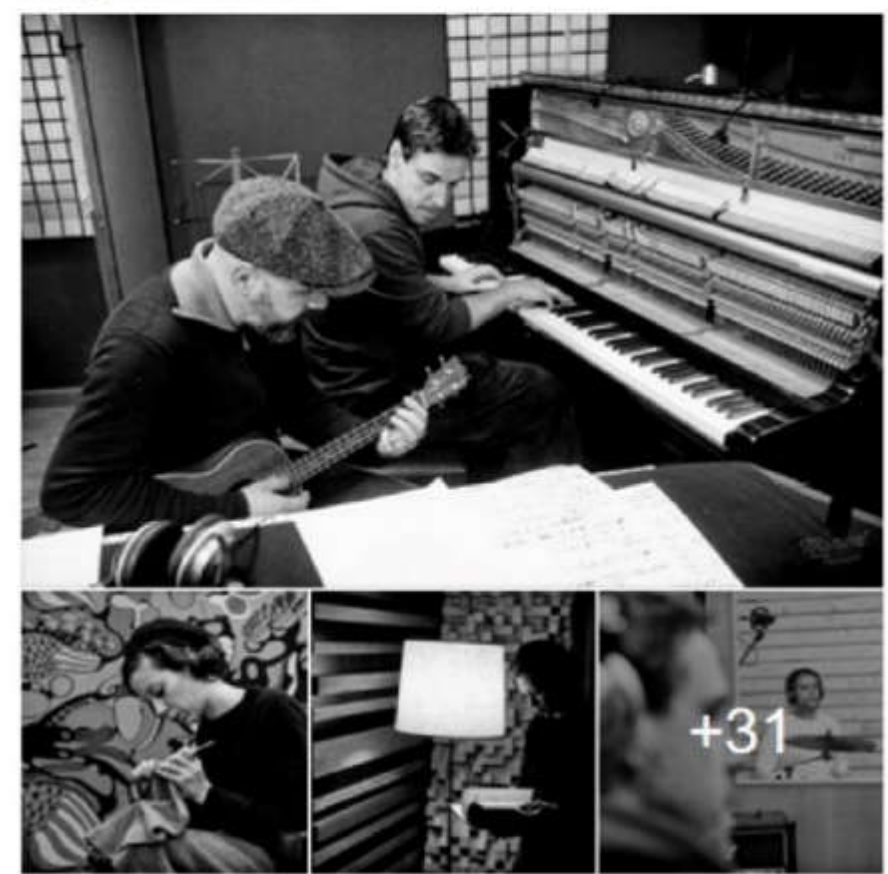

Manuel Portugal / Fotografia adicionou 34 fotos nowas ao atbum. The Soaked Lamb Recordings 2015 - com Panto Zurca e 5 outras pessoas. Gostar da Paigina 13 de janeito de $2015 \cdot 6$

Os The Soaked Lamb começaram a gravar o seu quarto album e corwidaram-me para documentar as gravaçð̃es em Fotografia e Video para jă aqui estăo as fotos da primeire sess lo. Mais para a frente conto ter um Mini-Doc sobre o que se passou nestes dias

It Gonto Comentar A Partillar

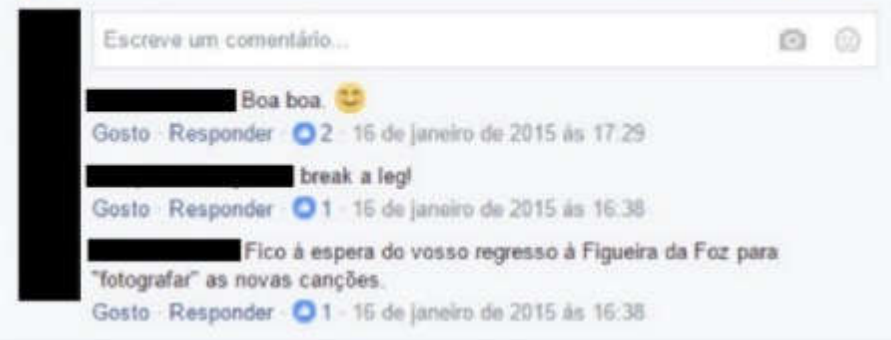

Comentários retirados do Facebook 
Comentando comentários: questões de texto, género e corpus

\section{Comentário}

\section{Exercer a cidadania} contra os banqueiros

Esta crónica é um apelo aos mais esclarecidos danossa urbe; um apelo aos homens de bom coraçāo que gostam da sua rua e amam a sua terra e as suas gentes. Os bancos têm falta de dinheiro por causa da crise. A grande matioria das pessoas está a levantar o seu dinheiroou a deixá-loà ordem para qualquer imprevisto. Anda uma azáfama danada nos aitos quadros dos bancos a imporem resultados aos gerentes das agências. A ordem é clara e nầ tem segredos; vendam aos novos e velhos, aos mais e menos esclarecidos, os produtos que mais interessam ao banco.
Precisamos de capital, nãopodemosadormecer, o dinheiro éo nosso negócio, quem não souber trabalhar perde o emprego.

É mais ou menos isto que os empregados dos bancos ouvem dos seus superiores quase diariamente impondo resultados ao final do més. Os clientes menos avisados, muitos deles com idade para serem filhos dos funcionários dos bancos, se não forem cautelosos vão continuar a investir as suas poupanças em produtos tóxicos. Quando precisarem do dinheiro ele já se evaporou nos negócios ruinosos dos banqueiros. Quando morrerem os seus herdeiros vão ficar com contas comprometidas em depósitos manhosos feitos par pessoas que precisam de garantir o seu emprego e por isso náo questionam mais a ética e as boas práticas do negócio.

Depois do BES vaificar tudoigual. Jánão há limites para quem domina o sistema. Depois do que se passou com Ricardo Salgado, que era considerado o príncipe dos banqueiros, odono disto tudo, o maior amigo dos politicos influentes que usam cravo na lapela, só nos resta acreditar em milagres.

Entretanto voltemos aos velhos tempose emvez de campanhas de alfabetizaçäo assumamos que é um dever de cidadania avisar os incautos sobre as intençōes dos banqueiros. Devemos e temos obrigaçâo de exercer a cidadania informando os nossos amigos, familiares e vizinhos sobre como podem defender-se dosenganos dos donos do dinheiro. Os juros dos depósitos a prazo são ridicu.
Los. Quem nầo sabe o mundo em que vive vai aceitar dois ou três por cento num produto sem retorno garantido. Anda tudo a dispa rar pólvora seca contra o que já nảo tem ré médio mas o sistema bancário vai continu. ar a tentar triturar aqueles que ainda náo cairam no conto do vigório

O curacüo mais negro da maldade fert com que Ricardo Salgado e o seu banco déxassem milhares de portugueses na pobreza depois de uma vida de trabalho. É justo que nanossarua, na nossaaldeio, na nossaterra, sejamos solidáriose avisemos os mais velhios eimpreparados para lidarem comos bancos avisando-os de que já näo há rendimentos nas contas a prazo. Se receberem ofertase porque lhes estäo a tramar a vida. JAE

Comentário retirado do Jornal de Leiria 


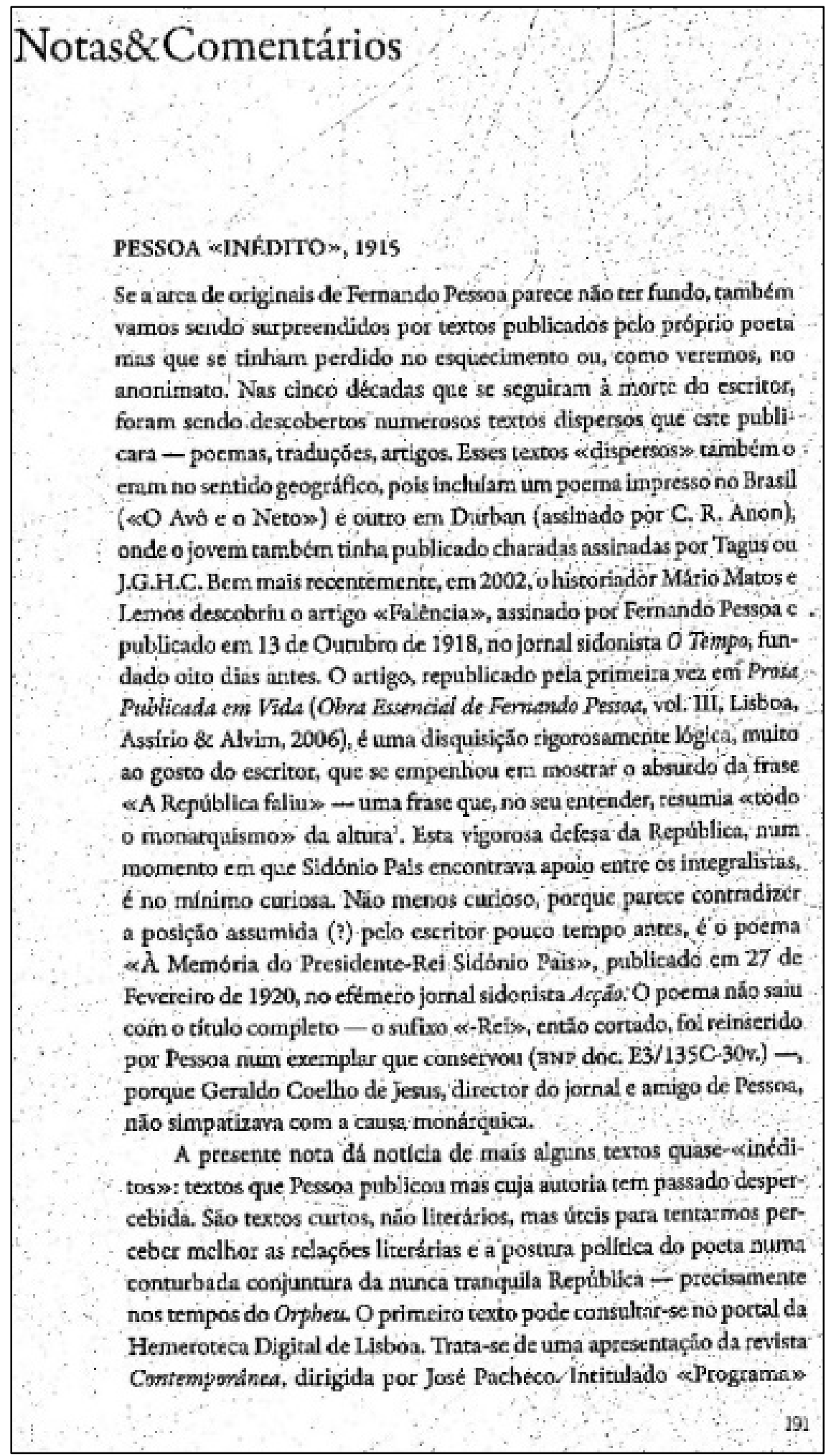


E publicado como uma separata do «número espécimen», o texto n̊̊o ć assinado. Pessoa, no entanto, reivindica a autoria $\mathrm{cm}$ duas listas de publicaçó́es suas ${ }^{2}$. Justificando a aecessidade e $o$ interesse da nova revista - uma das mais elegantes a ser fundadas naqueles anos -, o autor do texto explica:

Temos gente culat - mais do que se cré; nem há cntre nós a defieiência, que se julga, de espítitos qualifftcáveis de clegantes. Mas nío formam sociedade, náo se conceutram. Nŏo tèm sequer uma revista que saibsm que é lida petos seus pares com interesse, $\mathrm{c}$ en cujo manustimento, portanto, se saibann acoinpanbados por quantos consideram scus cougénercs

De aí o nảo terem os nossos artistas nem puáblico nem ao menos crítica. O público e a critica para as cousas de culturn, nío os eria o mero número de gente calea num pais, mas a facilidade corn quc, reunindo-sc, conjugardo-se ou pensando espontineamente cm comun, formats, nhio gente culta, mas propramente am meio culto.

Essa grande defieiéncia do nosso mcio, vem enfim CONTEMPORiNEA sup̣i-la.

E $v$ texto cstende-se por mais scte parígráas. O segundo parágrafo citado é de puro sabor pessoano, pois a formaçío de um meio culto era uma das suas grandes preocupaçóes enquanto educador e civilizador dos sens conterráneus.

O nímero espécimen de Contemporánea foi lançado en: Abril de 1915, portanto quase $\mathrm{cm}$ simultałnen com Orphetu (fins de Marco). Podemos imaginar uma troca de favores, vu serviços: José Pacheco desenlecu a capa do primeiro número de Orphetu, enquanto Pessoat redigin o texto de apresentaçáo da Contemporânen, cujja capa inaugural cra, por sta vez, obra de Almada Negreiros. Tudo $\mathrm{cm}$ familia — atéc certo ponto. Náo parece que tenha havido uma estratégia concertada de mútua afirmaçẳo, mas é certo que as duas revistas, sendo projectos muito diferentes, cram por isso mesmo complementares. Contemporatnea, chique e sumpruosa, destinava-se a uma elite cultural e mesmo endinheirada. Orpher, iconoclasta, apelava à clite intelectuail, com o intuito de perturbat e mudar a mentalidade de alguns.

Ençuanto Orphets teve ao menos um segundo número, Contemponînea morreu logo após o primeiro (o tal «espécimcn w), sú regressando à vida cm 1922, quando Pessoa se tornou un dos seus colaboradores mis atssíduos. O malogro da primcira tertıtiva editorial de jostế Pacheco talvez se devesse, em parte, ao claro apoio manifestado pela revista ao general limenta de Castro, que governava o pais sem parlamento desde finais de Jantiro e cujo governo foi derrubado em 14 de Maio. 
Em 13 de Maio de 1915, véspera da queda de Pimenta de Castro, saiu o panfleto politico Eh Real!, onde surge o coulhecido texto de Pessoa intitulado $«$ O Preconceito da Ordem $»$. Quase todos os colaboradores da publicaçío sc mostravam desiltudidos com a ditaduta pimentista, mas o alvo específico da sua revolta era o Integralismo Lusitano, que a ditadura protegia e no qual se apoiava, numa relaçúo simbióótica. O título irónico do panfleto sugeria, aliás, que o governo militar poderia condazir tho regresso da monarquia3. Quanto ao texto de Pessoa, afirma na sua primeira frase que a constante preocupaçắo com a Ordem é um dos « vários preconceitos cyue salpicaun as teses dos nco-monárquicos» e dedica-se, no resto do artigo, a destruí-lo. Náo se manifesta dircetamente contra Pimenta de Castro (cuja governaçã́o, aliás, defenderia mais tarce); a sua diatribe visa o Integralismo, como deixą claro um «comentário» seu que figum quase ne fim do panfleto: «linquato náo incide sobre o nosso integralismo e as suas origens uma crítica mais apertada, pode o curioso ir entretendo os scus mumentos com o livro de D. Parodi Traditionalisme et démocratie (Paris, Armand Colin, 1909). Ai as teses dos conservadores franceses (bise, como se sabe, dos nossos intrgyralistas) săo rcbatidas triunfantemente.

Trata-se de mais um pequeno «inédito $»$ que nắo o é̉ realmente, tendo a sta sutoria pessoana - atcstada pela primeira das listas de projectos já referidas ${ }^{4}$ - ficado oculta pelo mesmo motivo đ̣uc a do «1"rograma» da Contemporấnedt o texto năo fot assinado. Pessoa também identificou como seu o último «comentário», c portanto a última palavra, do panfleto: «... de modo que ele acabatá por implantar a Monatquia, para consolidar a República...». A frase é evidentemente irónica, mas o scntido da ironia náo é tấ claro. Parcece-me, no entanto, que serve de cpilogo a «O Preconceito da Ordem», apontando para a costradiçáo - imputável a Pimenta de Castro e ao Prestidente Manuel de Arriaga - de ceder aos integralistas e au seu apego à ordem, na esperança (no caso de Manuel de $\Lambda$ rriagaz), ou com a desculpa (no de Pimenta de Castro:), de nssim estabilizarem a República.

Quer sej̣a esta a interprecaçāo correcta da frase quer nuio, os dois cumentírios parcoem provar que Pessoa nîo cra um colahorador meramente casual do panfetro, Compartilhava a ideologia que o orientwa, pelo menos naquele momento, apesar de ter escrito, poucas semanas entes, en Abril de 1915, o texto de apreseritaçaio da revista Contempuráned, que contava, entre os seus colaboradores, trés altos dirigentes do Integralismo Lusitano: António Sardinha, Hipólito Raposo e Vasco de Carvalho.

Richard Zenith

Comentário retirado da revista Colóquio e Letras 